\title{
Modelling of the Lime Kiln at SSAB, Raahe
}

\author{
Tomas Lundberg ${ }^{1} \quad$ Joel Orre $^{1} \quad$ Timo Paananen $^{2} \quad$ Olli Mattila $^{2}$ \\ ${ }^{1}$ Swerim AB, Luleå, Sweden, \{joel. orre, tomas. lundberg\} @ swerim. se \\ ${ }^{2} \mathrm{SSAB}$, Raahe, Finland, \{timo.paananen, olli.mattila\} @ssab.com
}

\begin{abstract}
An OpenModelica model of the SSAB Raahe lime kilns has been developed in order to help in formulation of operation strategies and to choose important parameters to measure and monitor. The model is a dynamic simulation model describing the calcination process of limestone in the lime kiln.

Keywords: lime kiln, lime calcination, process modelling, dynamic simulation, dynamic model
\end{abstract}

\section{Introduction}

The steel industry is a major consumer of lime products. To produce $1000 \mathrm{~kg}$ of crude steel (using the integrated steelmaking route based on Blast Furnace (BF) and Basic Oxygen Furnace (BOF)), about $270 \mathrm{~kg}$ of limestone is needed (World Steel Association 2019). The estimated annual world production of lime is around 350 million tons, of which the steel industry uses between 140 and 160 million tons globally (Manocha and Ponchon 2018).

Lime has several usages in the steel making process. In the $\mathrm{BF}$, where iron ore is smelted into pig iron, limestone is used for the formation of slag as it accumulates the waste materials that are produced in the process. During basic oxygen steelmaking, where hot metal is converted into steel, quicklime is used in the BOF process both for phosphorus and sulphur removal and for slag formation.

The lime quality has an important impact on the steel quality, its metallurgical properties, and the total cost of production. If the lime is over-calcinated it starts sintering which leads to a reduction in the surface area and hence loss of reactivity. Similarly, if the lime is under-calcinated, it will still contain carbon dioxide in its core (see Section 2 for further details) which also lowers the reactivity and may also cause further problems during the BOF process. It is therefore important to have control over the lime quality.

An OpenModelica model of the SSAB Raahe lime kilns was developed in this study. The purpose of the model is to help in formulation of operations strategies and to aid in selecting important parameters to measure and monitor. Questions that the model can help answering is e.g. how the lime kilns should be operated during production stops and how to adjust the lime quality. The model is a dynamic simulation model describing the calcination process of limestone in the lime kiln.

In the literature, simulations of lime kilns have mostly been done with one-dimensional approaches (see e.g. (Bes 2006, Do 2012, Herz et al. 2015) and the references therein). More advanced three-dimensional Discrete Element Method-CFD (DEM-CFD) simulation has also been presented (Bluhm-Drenhaus et al. 2010; Krause et al. 2017). However, these simulations are quite computational extensive; the simulation performed by (Krause et al.2017) required about three weeks computational time on 2016 mainstream hardware. Our simulation is less detailed but doesn't require more than around 100 minutes computational time for about 24 hours simulated time, or about 4 minutes per hour simulated time (on an ordinary office laptop). This is short enough for enabling the model to be used as a practical tool for selecting the best operation strategies.

The paper is organised as follows. In Section 2 we give a short introduction to the calcination process, while Section 3 give a general overview of lime kilns. In Section 4 we describe the OpenModelica model, and Section 5 discusses the calibration of the model against production data. Finally, Section 6 contains a discussion of the results from modelling and we end the paper in Section 7 with the conclusions.

\section{Lime Production}

Lime is manufactured by burning limestone in kilns. The limestone is crushed into particles with a size ranging from a few centimetres up to around 10 centimetres. In the calcination process calcium carbonate is converted to calcium oxide and carbon dioxide. This is an endothermic process with the following reaction formula

$$
\mathrm{CaCO}_{3}+\text { heat } \longrightarrow \mathrm{CO}_{2}+\mathrm{CaO} \text {. }
$$

The required heat is supplied by burning fuel within the kiln.

On the particle scale, the actual calcination reaction is advancing from the surface of the particle to the centre, a so-called "shrinking core" process. Two steps are determining the rate: the heat transfer from the surrounding gas to the reaction front, and the transfer of the released $\mathrm{CO}_{2}$ through the particle to the surface where it is released to the surrounding gas.

To model the calcination process we have taken into account details of heat and mass transfer. We mainly have followed the approach by (Do|2012), to which we refer for further details. 


\section{Lime Shaft Kilns}

There are two basic types of lime shaft kilns in use today. A normal shaft kiln has a single vertical shaft where limestone is charged at the top and lime is discharged at the bottom. The lime and limestone move slowly downwards in the shaft by gravity. The calcination occurs in the middle of the kiln where fuel is combusted.

A Parallel Flow Regenerative (PFR) kiln is a more modern type of kiln which has two interconnected shafts (see Figure 1, left). Each shaft operates in two different modes, burning and non-burning, and while one shaft operates in the burning mode (calcinating the limestone), the other operates in the non-burning mode (preheating the limestone). Each shaft can also be divided into three different zones, the pre-heating zone, the combustion zone, and the cooling zone. A cross-over channel connects the two shafts at the bottom of the combustion zone.

In the burning mode, fuel is supplied through lances at the top of the combustion zone. Combustion air is supplied under pressure at the top of the kiln (at the top of the pre-heating zone). The combustion gases pass through the crossover channel from the burning shaft into the nonburning shaft, where they flow upwards and exit at the top of the non-burning shaft. The flow of gases therefore changes direction when the shaft shifts from burning to non-burning. During the passage, the off-gases transfer heat to the limestone in the non-burning shaft. Cooling air is entering the shaft at the bottom of the cooling zone. The flow of gases changes direction at regular intervals of about 15 minutes, which is called a half cycle. Another flow reversal completes the cycle.

Limestone is supplied at the top of the shaft. Lime and limestone travels slowly down through the shaft by gravity. During the non-burning mode, the stone in the preheating zone is heated by the combustion gases, while during the burning mode the stone transfers heat to the combustion air. The stone in the pre-heating zone thus acts as a regenerative heat exchanger.

To the right in Figure 1 is the temperatures profile for one of the shafts. The profile should be thought of as following a mass particle from the top of the shaft to the bottom. The vertical axis is therefore a combination of time and location in the shaft. The variation in temperature due to switching between burning and non-burning mode can be seen clearly.

\subsection{The Lime Kilns at SSAB Raahe}

There are two PFR shaft kilns in Raahe with production capacity of 280-330 ton/day and 300-420 ton/day, respectively. They are operated with different types of limestones sizes, between 40 and $70 \mathrm{~mm}$ for lime kiln 1 and between 60 and $90 \mathrm{~mm}$ for lime kiln 2. Due to the size distribution of the limestones a good burned lime product still contains about $2.5 \% \mathrm{CaCO}_{3}$, which is found in the core of the larger pieces. As discussed in Section 1 both over-calcination and under-calcination is bad. However, because most of the limestone is used in BOF the worst case is when the quality varies since this gives bad energy predictions.

One difference between the lime kilns at SSAB Raahe and the general description in Section 3 is that the combustion air is not supplied at the top through pre-heating zone; instead it is mixed with Coke Oven Gas (COG) and injected through the lances.

\section{Lime Kiln Modelica Model}

The lime kiln Modelica model is built up in a modular fashion. At the top level there is a total model for a single shaft including pre-heating, combustion and cooling. Each of these three zones are in turn modelled in separate sub-models. The sub-models will be described further below.

The models use mass and energy balances together with reaction kinetics according to calcination and a simple flame model. SSAB has done tests on the used limestones at one temperature which is used as a base for formulating a shrinking core model of limestone calcination.

\subsection{Total Model}

The total model is shown in Figure 2 It consists of three sub-models which corresponds to the three zones in a PFR lime kiln. The three sub-models, the pre-heating model, the combustion model, and the cooling model, will be described further below.

In the model we only consider one of the two parallel shafts explicitly. The two distinct modes of operations for a PFR lime kiln, burning and non-burning, are modelled using off-line tables which specify the times for burning and non-burning. The cross-over channel between the two shafts in a PFR kiln is modelled by adding a gas sink and a gas source between the combustion zone and the cooling zone. The sink is used during the burning mode where in a two-shaft PFR the combustion gases would have been used to heat the stone in the non-burning shaft. Similarly, the gas source is used during the non-burning mode to mimic the transfer of combustion gases to the non-burning shaft. The gas flow parameters for the sink and the source are governed similarly as the burning times, i.e. using offline tables. The data in the tables is taken from process data.

Using a single shaft in the model in this way greatly reduces the complexity of the model, but at the expense of some flexibility in the modelling since it requires process data.

\subsection{Combustion Model}

We start by describing the combustion model (see Figure 3). The same model (with small modifications) is also used in the other two models, the pre-heating model and the cooling zone model.

The combustion model is used for modelling the middle part of the kiln, where the limestone is decomposed in lime and $\mathrm{CO}_{2}$. Since the decomposition of limestone 


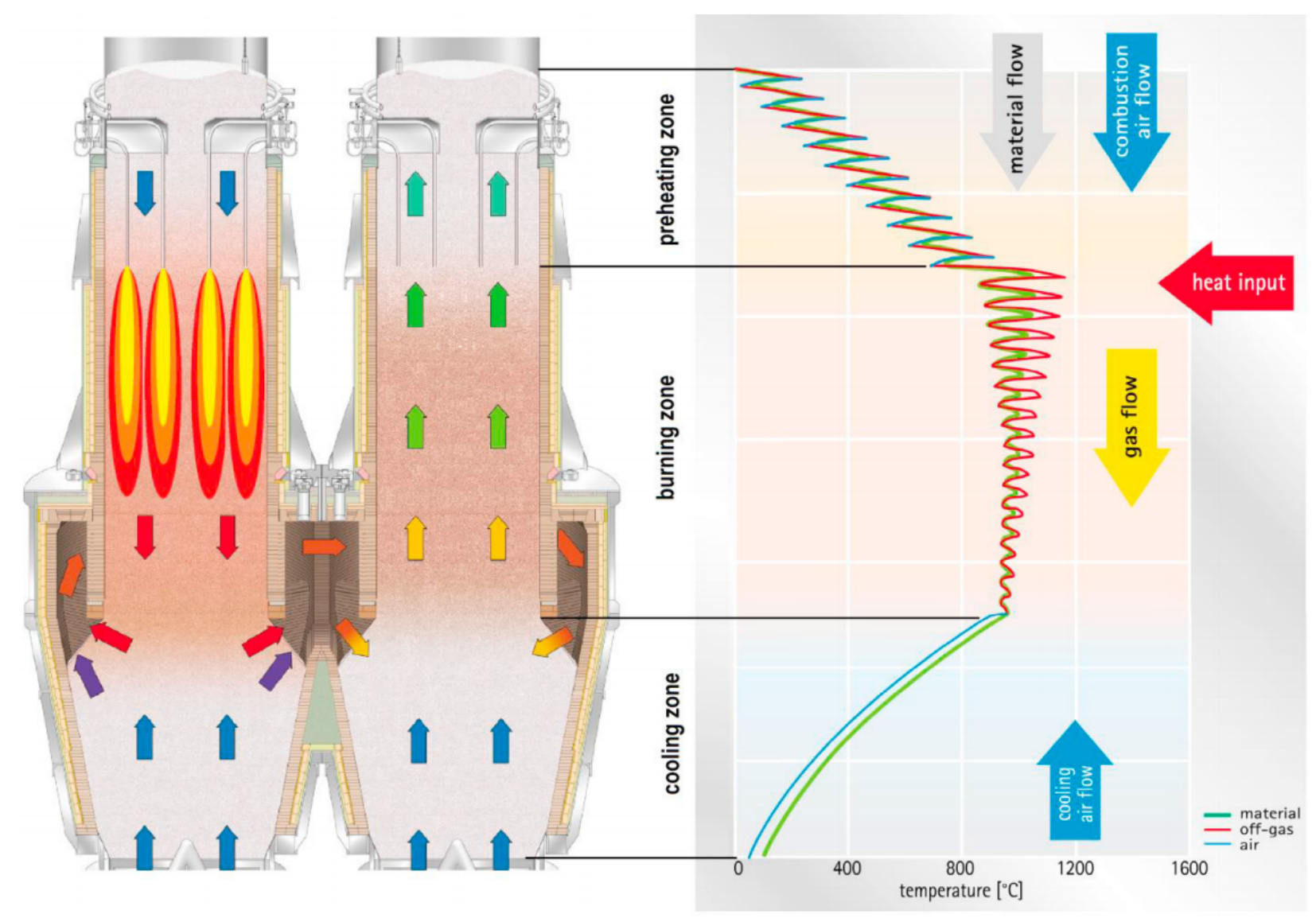

Figure 1. Operating principle and temperature profile of a PFR lime kiln. Taken from (Piringer 2017).

is an endothermic process it needs an energy supply. The heat needed for the calcination is generated by burning fuel (COG) in the combustion zone, and the fuel (together with the combustion air) is introduced in the combustion zone through lances at the top of the zone.

The combustion model is conceptually quite simple. As input it takes the gas and lime/limestone mass flows from the pre-heating model. The output is the resulting gas and lime/limestone mass flows which is used as input to the cooling model. Notice that for the gas flow, "input" and "output" is here used conceptually and should not be interpreted literally. The direction of the actual gas flow varies depending on the mode of the shaft: in the burning mode the direction of the gas flow is from the pre-heating model to the combustion model ("downwards" in this conceptual view), while in the non-burning mode the direction is from the combustion model to the pre-heating model ("upwards").

The core of the combustion model is a limestone model and a packed bed model.

The limestone model is responsible for the actual modelling of the conversion from limestone to lime. This model is based on the shrinking core reaction rate calculations (see e.g. (Do 2012)). The decomposition of limestone into lime releases $\mathrm{CO}_{2}$ which is fed back to the packed bed model and included in the gas flow.
The packed bed model is responsible for the modelling of the gas flow through the limestone. Additionally, it calculates the heat transfer between the gas and the limestone. The total amount of available heat is calculated from the COG flow based on the heat of combustion. In order to model the physical extent of the flame, the combustion is divided into a number of sections, basically by just stacking identical sections of the combustion model on top of each other. We have used a model with $20 \mathrm{sec}-$ tions.

The actual size of the flame is not known with certainty, and therefore the heat produced by the flame is divided between the sections by specifying the fraction of the total heat produced that is available in a given section. In the simulations we have performed, the flame extends through the 13 topmost sections, and where the highest amount of heat is delivered in the top-most sections and decreasing towards the bottom.

There are some unknown factors which need to be taken into account in the combustion model, such as the heat losses to the surroundings. Another factor is the uncertainty in the measured value of the heating value for the COG. We have taken these factors into account in an empirical way by lowering the measured heating value slightly with approximately $12 \%$, and thus decreasing the amount of heat delivered as calculated from the COG flow 


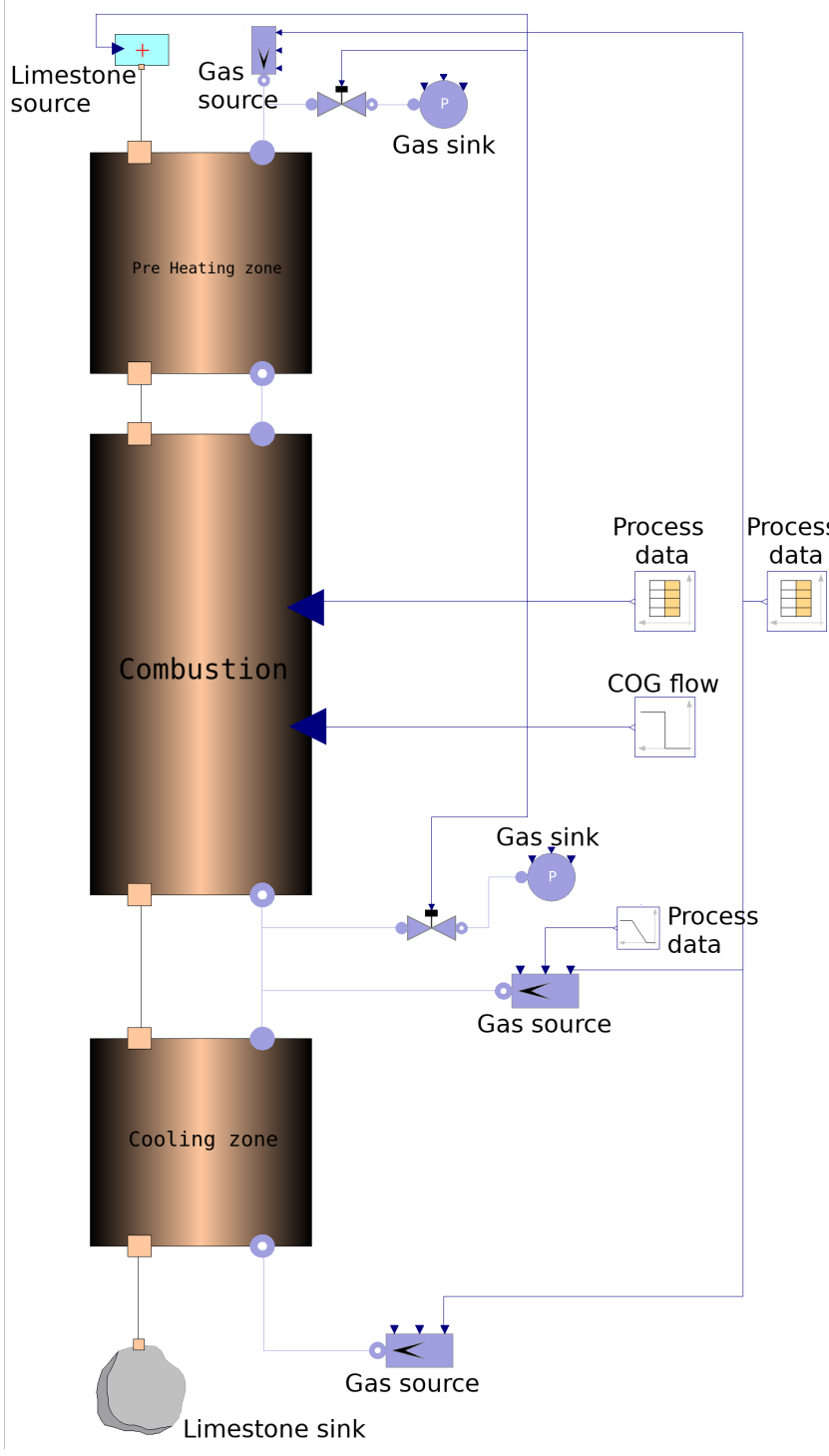

Figure 2. Total lime kiln model.

in the model. The value was determined from fitting the model to process data.

A pressure drop is also inserted in the gas flow to model the gas flow resistance.

\subsection{Pre-heating Model}

The pre-heating model is in principle identical to the combustion model. Basically, the only difference is that there is no combustion and consequently the COG flow is not used as input. Similar to the combustion model, the preheating model is also divided into sections and as in the combustion model we have used 20 sections also in the pre-heating model.

The input to the pre-heating model is the mass flow (i.e. the limestone inserted at the top of the kiln) and gas flow (both derived from tables as described for the total model in Section 4.1).

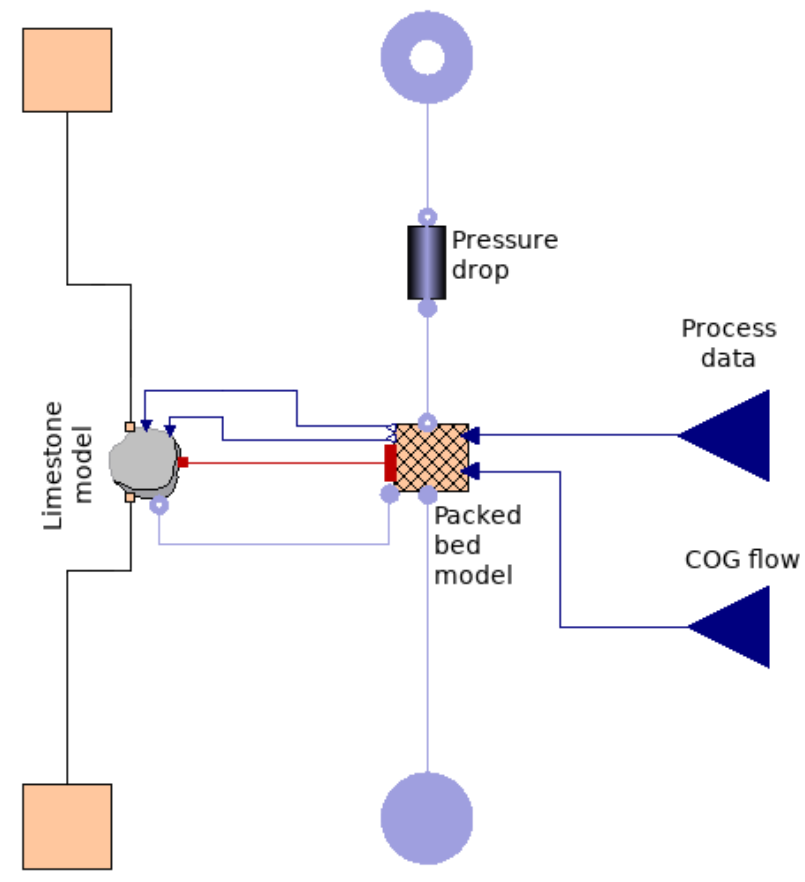

Figure 3. The combustion model. The gas flow is shown in blue and the limestone flow in beige.

\subsection{Cooling Model}

The model for the cooling zone is identical to the preheating model. The input to the cooling model is the mass flow and gas flow from the combustion model. The finished lime is received by a "lime sink".

\section{Model Calibration}

The shrinking core model describing limestone calcination is calibrated with data from laboratory tests studying the calcination. The laboratory test were done through preheating a limestone cylinder with a diameter of $20.8 \mathrm{~mm}$, a height of $20.5 \mathrm{~mm}$, and an initial mass of $18.5 \mathrm{~g}$ to $800^{\circ} \mathrm{C}$. The limestone was then put into a furnace with constant power applied and with a temperature of $950^{\circ} \mathrm{C}$. In the furnace, the mass of the limestone and the temperature close to the limestone were measured. This laboratory test was then modelled with limestone calcination based on shrinking core model found in (Do 2012), with a slight difference on how the heat conduction is modelled. In our model the heat conduction is modelled outside the shrinking core model for more precise heat transfer. The following constants were calibrated:

- heat conduction constant for limestone: $\lambda=$ $0.6 \mathrm{~W} /(\mathrm{m} \cdot \mathrm{K})$,

- diffusion constant for $\mathrm{CO}_{2}: d_{p}=2 \times 10^{-4} \mathrm{~m}^{2} / \mathrm{s}$,

- reaction rate constant: $k=8 \times 10^{-3} \mathrm{~m} / \mathrm{s}$.

These constants give similar rate of calcination in the model compared to the laboratory test as seen in Figure 4 


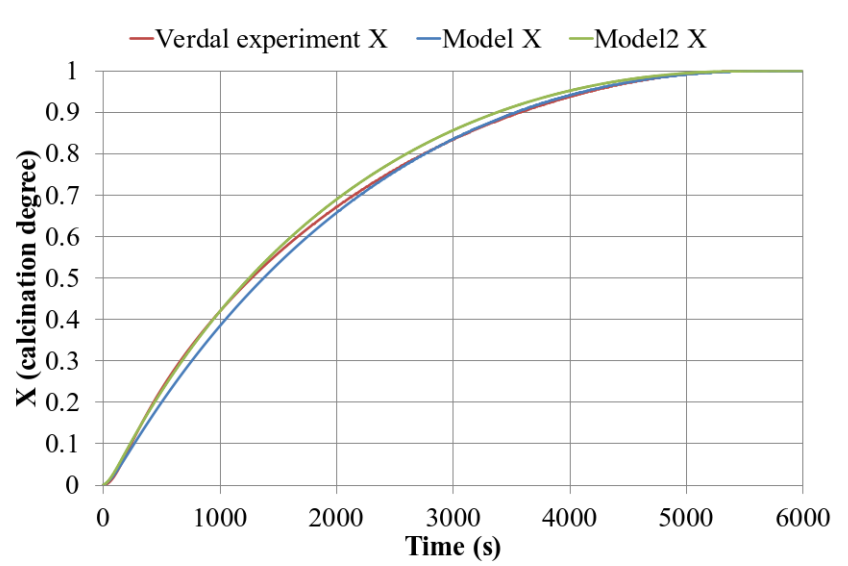

Figure 4. Calcination degree of calibrated model (Model X), updated calibrated model (Model2 X) and laboratory test (Verdal experiment $\mathrm{X}$ ).

The heat conduction constant $\lambda$ was later changed from 0.6 to 0.55 in order to achieve better calibration with lime kiln process data. This updated $\lambda$ in Model 2 has good correlation to the laboratory test in the first $1500 \mathrm{~s}$ (see Figure 47). To achieve even better calibration of calcination constants it would have been preferable to have laboratory tests on at least two different furnace temperatures for the same limestone, but it has not been done in this case.

Concerning the gas-solid heat transfer coefficient we have followed (Do|2012) and references cited therein. The heat transfer coefficient $\alpha$ can be calculated from the Nusselt number in the packed bed (Do 2012). In order to make the energy balance easier, they introduced a modified heat transfer coefficient which assumes a homogeneous average temperature instead of having a temperature distribution in the radial direction in the particle due to that the heating-up and cooling-down of the solid particles is a transient process. Additionally, we added a factor to the $\alpha$ constant for calibrating the heat transfer. Our modified heat transfer coefficient $\alpha_{\text {mod }}$ is then given by

$$
\alpha_{\text {mod }}=k_{\alpha}\left(\frac{1}{\alpha}+\frac{d / 2}{\kappa \lambda}\right)^{-1}
$$

where $k_{\alpha}$ is the calibration constant, $\lambda$ is the thermal conductivity of the solid particle, $d$ the particle diameter, and $\kappa$ is a transient factor which equals 5 for a sphere. The value for our $\alpha_{\text {mod }}$ in the calibrated OpenModelica model ranged from $27 \mathrm{~W} \mathrm{~m}^{-2} \mathrm{~K}$ to $29 \mathrm{~W} \mathrm{~m}^{-2} \mathrm{~K}$, which is reasonably close to heat transfer coefficients found in (Senegačnik et al.|2007). The modified heat transfer coefficient enters in the energy balance equations, e.g.

$$
\dot{M}_{s} c_{p s} \frac{d T_{s}(z)}{d z}=\alpha_{\bmod } A O(1-\psi)\left(T_{s}(z)-T_{g}(z)\right),
$$

where $\dot{M}_{s}$ is the mass flow of lime, $c_{p s}$ its specific heat capacity, $A$ the cross-sectional area of the furnace, $O$ the specific surface of the lime in $\mathrm{m}^{2} / \mathrm{m}^{3}, \psi$ the void fraction, $T_{s / g}$ the temperature of the lime and the gas, respec-

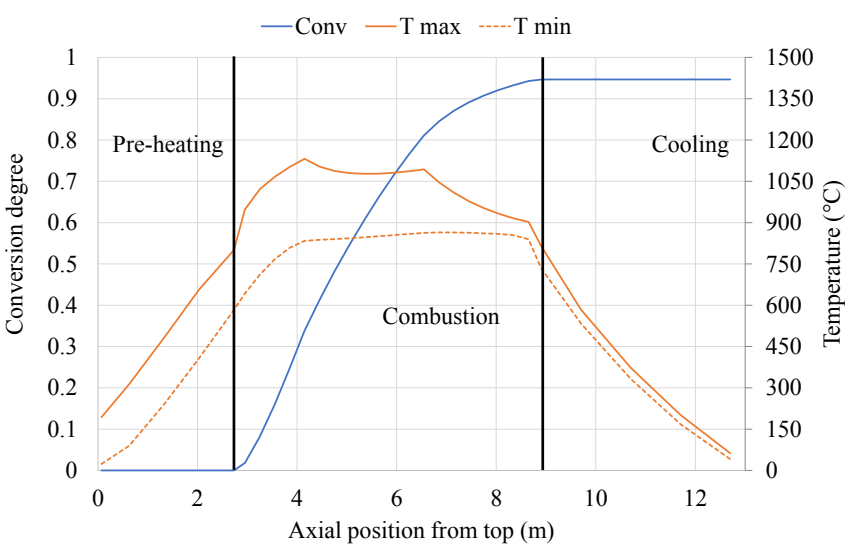

Figure 5. The steady-state conversion profile of limestone (blue) together with the maximum and minimum gas temperature (orange).

tively, and $z$ the position along the height of the kiln. In our model we have used a void fraction of 0.38 .

\section{Simulation Results and Discussion}

We have applied our model to one of the lime kilns in Raahe. From the model it is possible to obtain e.g. the gas temperature and conversion profile of the limestone. Figure 5 shows the steady-state conversion profile, averaged over one complete cycle, together with the maximum and minimum temperature for the gas during one cycle.

As a more advanced example of application for our model, we have used it to study how to best continue operation of the kiln after a stop. We used process data for 24 hours as input, which included a production stop lasting a couple of hours.

The lime kiln operating conditions before and after the stop is similar, i.e. same cycle time and limestone charge.

Figure 6 shows temperature measurements in two locations in the cross-over channel. The temperature decrease in the channel during the stop is around $50^{\circ} \mathrm{C}$ to $60^{\circ} \mathrm{C}$. Based on this, the temperature decrease in the modelling is assumed to be $50^{\circ} \mathrm{C}$ in large part of the furnace (where the temperature of the lime is over $500^{\circ} \mathrm{C}$ ).

We have studied three different approaches to start the kiln after a stop. Description of these cases, together with the "Steady state" nominal case, is found in Table 1 . In the three cases concerning how to restart the kiln, lime/limestone temperature is assumed to have cooled with $50{ }^{\circ} \mathrm{C}$ in the warm part of the lime kiln. No calcination is assumed to take place during the stop, which is a good assumption if there is no gas flow in the lime kiln during the stop. The reason for this is that the partial pressure of $\mathrm{CO}_{2}$ prevents further calcination already when only a small amount of calcination has taken place. On the contrary, with only small flow of air the calcination continues significantly.

The heat loss during this particular stop corresponds to approximately the same amount of heat that is added to the lime kiln during a half cycle, or, equivalently, about $50 \%$ of the COG used in one cycle. The heat loss can therefore 
Table 1. Simulation cases.

\begin{tabular}{ll}
\hline Case name & Description \\
\hline $\begin{array}{l}\text { Steady state } \\
\text { Normal }\end{array}$ & $\begin{array}{l}\text { Based on average values from process data before the stop. } \\
\text { Simulation of process data conditions after stop. Operation continues in same way } \\
\text { as before stop with the change that limestone/lime temperature starts } 50^{\circ} \mathrm{C} \text { lower } \\
\text { (in large part of lime kiln). }\end{array}$ \\
LOG & $\begin{array}{l}\text { Limestone/lime temperature starts } 50^{\circ} \mathrm{C} \text { lower than before stop. The first cycle is } \\
\text { operated with higher } \mathrm{COG} \text { flow }(150 \% \text { of normal operation conditions) }\end{array}$ \\
Half cycle & $\begin{array}{l}\text { Limestone/lime temperature starts } 50^{\circ} \mathrm{C} \text { lower than before stop. The discharging } \\
\text { of lime starts after a half cycle instead of directly after stop. Combustion is done } \\
\text { in both shafts with combustion time halved. }\end{array}$ \\
\hline
\end{tabular}

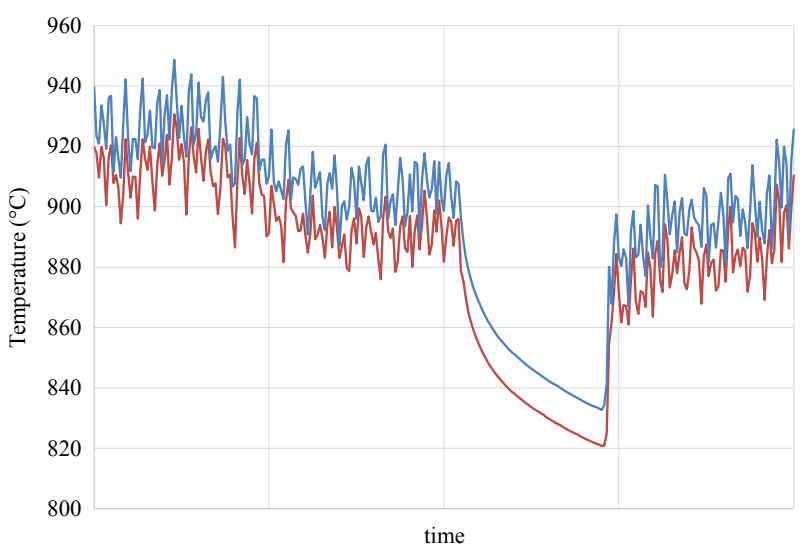

Figure 6. Temperature measurements in the cross-over channel for two different locations. The effect on the temperature by the production stop can clearly be seen.

be compensated either by delaying the lime discharge for one half cycle (the "Half cycle" case) or by increasing the flow of COG with $50 \%$ for one cycle (the "COG" case).

Figure 7 shows the percentage of $\mathrm{CO}_{2}$ in the discharged lime while Figures 8 and 9 show the rate of calcination and the average gas temperatures for the four cases, where the values have been averaged over the three first cycles after the stop. Comparison with the steady state conditions show that the percentage of $\mathrm{CO}_{2}$ in lime for the "Normal" case is increased at $5 \mathrm{~h}$ to $22 \mathrm{~h}$ after start with almost $1.5 \%$ at its peak.

The "COG" case gives slightly lower $\% \mathrm{CO}_{2}$ in lime at $6 \mathrm{~h}$ to $11 \mathrm{~h}$ and slightly higher $\% \mathrm{CO}_{2}(0.45 \%$ at peak $)$ at $12 \mathrm{~h}$ to $20 \mathrm{~h}$ after operation has continued after stop. This is due to a lower rate of calcination in the first part of the combustion zone (at $2.8 \mathrm{~m}$ to $4 \mathrm{~m}$ in Figure 8 ) and a lower temperature in the pre-heating zone and first part of the combustion zone (at $5 \mathrm{~m}$ to $7 \mathrm{~m}$ in Figure 9 in the first cycles after stop.

In the "Half cycle" case there is a slight increase $(0.35 \%)$ in the $\% \mathrm{CO}_{2}$ at $5 \mathrm{~h}$ to $9 \mathrm{~h}$ and a slight decrease $(-0.3 \%)$ in $\% \mathrm{CO}_{2}$ at $10 \mathrm{~h}$ to $16 \mathrm{~h}$. The reason for this is a warmer and more calcinated upper part of the lime kiln and a colder lower part of the lime kiln (see Figures 8

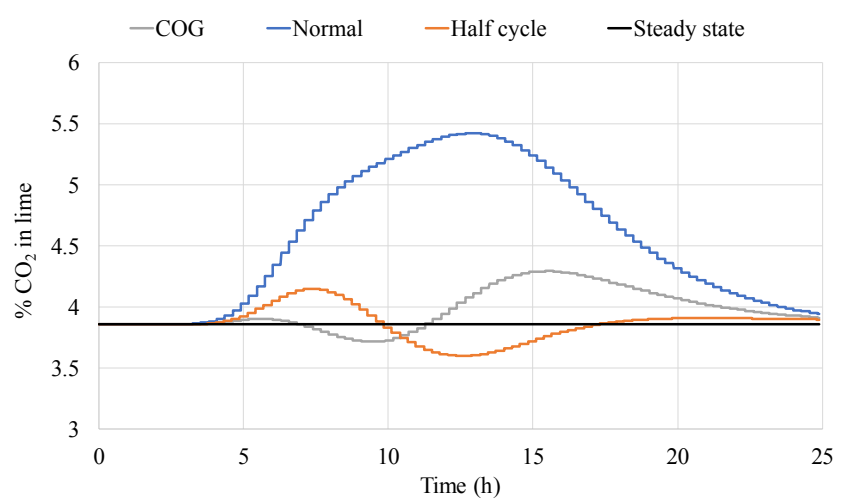

Figure 7. The percentage of $\mathrm{CO}_{2}$ in the discharged lime.

and 9). The colder lower part of the kiln is largely due to cooling air flowing through cooling zone without lime discharging.

Both adding extra COG and delaying the start of discharging lime after a stop in order to compensate for the heat lost during a stop seems to be beneficial to minimise variations in $\% \mathrm{CO}_{2}$ in lime. With different length of stop and operating conditions the amount of extra energy must be adjusted to correspond to the actual heat loss.

\subsection{Limitations in the Modelling}

One part of the model that lacks detailed information is flame modelling. Currently, the flame length and its profile for heat release is needed as input to the model. The longer the flame length, the more it extends into the crossover channel, and consequently the more the temperature in the channel varies (Piringer 2015). To improve the model, the properties of the flame should be investigated further.

Another part of the modelling that needs manual input is the temperature decrease during an operation stop. A temperature profile of the lime kiln based on process data on channel temperature is assumed when starting lime kiln operation after a stop. Model development together with extensive analysis of process data and probably some tests must be done to enable good simulation of temperature change during a stop. Consequently, it seems that the sim- 


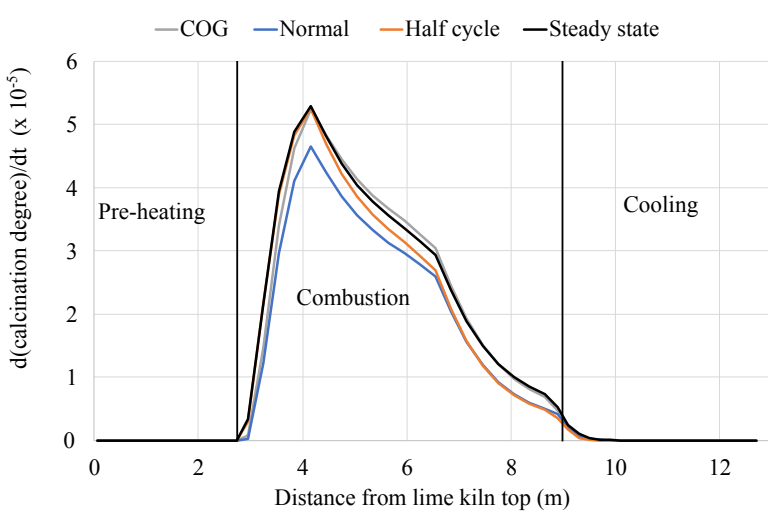

Figure 8. The average rate of calcination in the lime kiln for steady state and the three first cycles for the "Normal", "COG", and "Half cycle" cases.

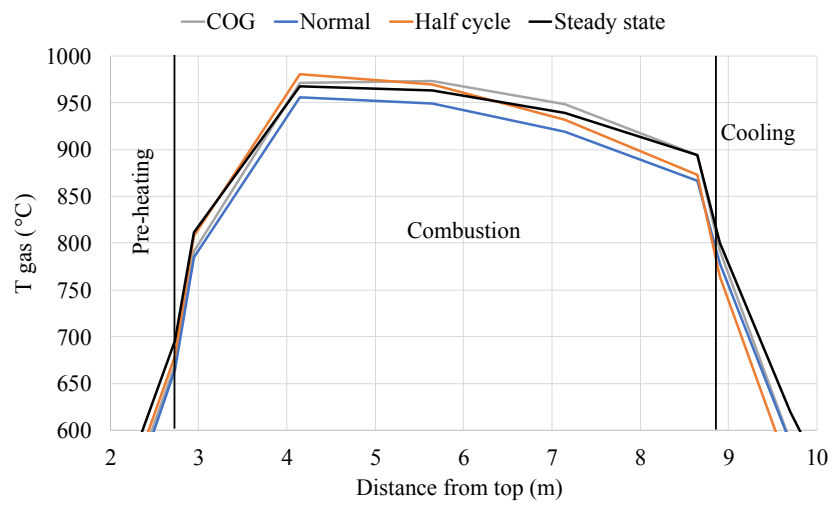

Figure 9. Average gas temperatures for steady state and the three first cycles for the "Normal", "COG", and "Half cycle" cases.

plest way is to assume a temperature loss and a temperature profile of the lime kiln depending on stop time.

\section{Conclusion}

We have developed an OpenModelica model of the PFR lime kilns at SSAB in Raahe. The model is a dynamic simulation model describing the calcination process of limestone in the lime kiln. The purpose of the model is to help in formulation of operations strategies and to aid in selecting important parameters to measure and monitor.

We have used the model to simulate a situation with a production stop for three different approaches on how to restart the kiln after the stop. The results from these simulations show that the model can indeed be useful for deciding operation strategies.

\section{References}

Agnieszka Bes. Dynamic Process Simulation of Limestone Calcination in Normal Shaft Kilns. PhD thesis, Otto-vonGuericke-Universität, Magdeburg, 2006.

T. Bluhm-Drenhaus, E. Simsek, S. Wirtz, and V. Scherer. A coupled fluid dynamic-discrete element simulation of heat and mass transfer in a lime shaft kiln. Chemical Engineering Science, 65(9):2821 - 2834, 2010. ISSN 0009-2509. doi: $10.1016 /$ j.ces.2010.01.015

Duc Hai Do. Simulation of Lime Calcination in Normal Shaft and Parallel Flow Regenerative Kilns. PhD thesis, Ottovon-Guericke-Universität, Magdeburg, 2012.

F. Herz, B. Hallak, E. Specht, R. Gröpler, and G. Warnecke. Simulation of the limestone calcination in normal shaft kilns. In 10th European Conference on Industrial Furnaces and Boilers (INFUB), 7-10 April 2015.

Bastian Krause, Birk Liedmann, Jens Wiese, Patrick Buchera, Siegmar Wirtz, Hannes Piringer, and Viktor Scherer. 3DDEM-CFD simulation of heat and mass transfer, gas combustion and calcination in an intermittent operating lime shaft kiln. International Journal of Thermal Sciences, 117: 121-135, 2017. doi:10.1016/j.ijthermalsci.2017.03.017

Sanjeev Manocha and François Ponchon. Management of lime in steel. Metals, 8:686, 08 2018. doi:10.3390/met8090686

Hannes Piringer. Key factors to minimise emissions from parallel flow regenerative lime kilns. Technical Report 11, ZKG International, 2015.

Hannes Piringer. Lime shaft kilns. Energy Procedia, 120:75-95, 2017. doi:10.1016/j.egypro.2017.07.156.

Andrej Senegačnik, Janez Oman, and Brane Širok. Analysis of calcination parameters and the temperature profile in an annular shaft kiln. part 1: Theoretical survey. Applied Thermal Engineering, 27(8):1467-1472, 2007. ISSN 13594311. doi $10.1016 /$ j.applthermaleng.2006.10.001.

World Steel Association. Fact sheet - steel and raw materials, 2019. URL https: //www.worldsteel.org/en/dam/jcr: f07b864c-908e-4229-9f92-669f1c3abf4c/ fact_energy_2019.pdf. 